\title{
Gene expression profiling of experimental saccular aneurysms using deoxyribonucleic acid microarrays
}

\author{
R. Kadirvel' ${ }^{1}$, Y.-H. Ding ${ }^{1}$, D. Dai ${ }^{1}$, D.A. Lewis ${ }^{1}$, S. Raghavakaimal' ${ }^{2}$ H.J. Cloft' ${ }^{1}$, D.F. Kallmes ${ }^{1}$ \\ ${ }^{1}$ Neuroradiology Research Laboratory; ${ }^{2}$ The Genomics Research Center, Mayo Clinic College of Medicine, Rochester, Minn
}

\section{Munish Kumar}

Department of Anesthesia and Intensive Care, PGIMER, Chandigarh

\section{Background}

Intracaranial aneurysm is described as cerebrovascular disorder which causes the localized dilation of blood vessel in brain. Recent studies have shown that it is multifactorial disorder which involve more than one risk factor resulting in the damage of blood vessel. ${ }^{1}$ Various studies including microarray have reported reliable feedback for detecting the role of different genes in aneurysm. ${ }^{2,3}$ In current study authors use microarray chip technology to analyse multiple gene expression at two different time points in rabbits.

\section{Methods}

Authors have used rabbit elastase model of aneurysm to study the effect of multiple genetic factors in pathology of disease. A rabbit gene chip was constructed. Investigators selected 400 genes out of which 209 genes with their sequence information was available in GenBank data base. Aneurysm tissue samples were nurtured for 8 days and 12 days. RNA extraction and synthesis was followed by microarray analysis of genes. After scan- ning authors selected 10 genes and quantified their expression through RT-PCR.

\section{Implications}

The above mentioned model explains the role of different genes including their expression based on time. However, authors were not able to elucidate the role of single gene but also provides perspective to study the time based expression of different genes does affect the disease pathology.

doi : $10.5214 /$ ans. 0972.7531 .210307

\section{References}

1. Nahed BV, Bydon M, Ozturk AK, et al. Genetics of intracranial aneurysms. Neurosurgery. 2007; 60: 213-25.

2. Mukherjee S, Belbin TJ, Spray DC, et al. Microarray technology in the investigation of diseases of myocardium with special reference to infection. Front Biosci. 2006: 11: 1802-13.

3. MacDonald TJ, Pollack IF, Okada $\mathrm{H}$, et al Progression-associated genes in astrocytoma identified by novel microarray gene expression data reanalysis. Methods Mol Biol. 2007; 377: 203-223. 